\title{
Promoting Cultural Connotation of Tourism by Protecting Language Diversity
}

\author{
Chen Tang ${ }^{1, a}$, Wang Jue ${ }^{2, b}$, Zhang Yu-xiü,c,* \\ ${ }^{1}$ School of Humanities \& Law, Hainan Radio \& TV University, Haikou, Hainan, China \\ ${ }^{2}$ School of International Tourism, Hainan Radio \& TV University, Haikou, Hainan, China \\ ${ }^{3}$ School of Humanities \& Law, Hainan Radio \& TV University, Haikou, Hainan, China \\ a1164126791@qq.com, b1205356898@qq.com, c317596380@qq.com
}

${ }^{*}$ Corresponding author

Keywords: Language Diversity, Cultural Diversity, Tourist Resources, Language Protection.

\begin{abstract}
The strategic value of cultural resources has now risen to the national strategy level. Languages are not only important cultural resources, but also part of non-material cultural resources. They play an important role in passing on human civilization and maintaining cultural diversity. However, with the integration of scattered ethnic groups into the national and global cultural system, the varied and abundant language ecology has been damaged, which has or will bring about the extinction of non-dominant languages. This paper is intended to appeal for the country's legislation, the society's propelling and the citizens' consciousness in protecting their languages. The diversity of languages is also a special cultural resource for tourism and requires researching, excavating, sorting out and protecting.
\end{abstract}

\section{保护语言多样性提升旅游文化内涵 \\ 陈 棠 $1, \mathrm{a}$ 王珏 $2, \mathrm{~b}$ 张玉秀 $3, \mathrm{c},{ }^{*}$ \\ 1 海南广播电视大学文法学院, 海口, 海南, 中国 \\ 2 海南广播电视大学国际旅游学院, 海口, 海南, 中国 \\ 3 海南广播电视大学文法学院, 海口, 海南, 中国

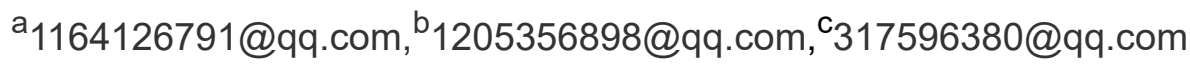 \\ “通讯作者}

关键词: 语言多样性; 文化多样性; 旅游资源; 语言保护

中文摘要. 当前, 文化资源的战略价值已上升到国家战略层面。语言是一种重要的文化资源, 也是非物质文化资源的重要组成部分, 对于传承文明和保持文化多样性具有重要作用 ${ }^{[1]}$ 。但 随着分散的族群逐步融入到国家以及全球文化体系中, 丰富多样的语言生态受到破坏, 越来 越多弱势语言已经消亡或正面临消亡的危险, 迫切需要从国家层面立法、社会层面推动和公 民层面树立自觉自信来加以保护。对于国际旅游目的地, 语言的多样性也是独具鬼力的旅游 文化资源, 亟待研究、挖掘、整理和保护。

\section{1. 引言}

语言是文化的载体, 是社会习俗、社会风尚的反映, 是人类思想和智慧的结晶, 也是旅 游资源的重要组成部分, 承载着 “少小离家老大回, 乡音无改髸毛衰” 的乡愁。随着分散的 
族群逐步融入到国家以及全球文化体系中, 社会、人口以及政治因素都在促使许多语言迅速 消亡, 且某些弱势语言消亡的速度越来越快。语言的消失就是人类文化文明的缺失, 对人类 而言是巨大的损失。政府和社会各阶层应以保护语言的多样性为己任, 以对人类文化文明负 责的态度，对现存语言进行研究、挖掘、整理和保护。

\section{2. 语言、文化、乡愁}

社会学家认为, 语言是文化的基石一一没有语言, 就没有文化; 从另一方面看, 语言又 是文化的一面镜子。可以说, 语言反映一个地区、一个族群的特征, 它不仅包含着该族群的

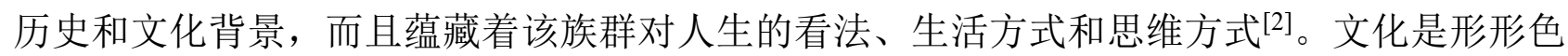
色的, 语言也是多种多样的。语言的多样性代表了文化的多样性。联合国教科文组织 2005 年 10 月 20 日于巴黎通过的《促进和保护文化表现形式多样性公约》就重申语言多样性是文化 多样性的基本要素之一[3]。语言也是数十代乃至数百代人的身份记忆和情感纽带。在中国, 乡音代表着乡土乡情乡愁, 在传统文化里是认祖归宗、实现身份认同的重要凭证。我国台湾、 香港、澳门地区都通用汉语方言, 在海外使用汉语方言的人口更多达 1000 多万, 遍布全球各 地，语言及其中包含的文化信息和乡愁意味不言而喻。

以海南岛为例, 研究者发现, 在这个面积 3.39 万平方公里的岛上生活着汉、黎、苗、回、 壮、瑶、侗等 30 个少数民族, 使用汉语、黎语、临高话、村语、勉语、回辉话、壮语等 14 种彼此不能通话的语言和方言; 汉语 10 大方言中, 海南岛占了 7 种。早期历史上多次移民将 语言带上岛后, 由于交通闭塞少受干扰, 许多语言现象保留了最初形态, 形成今天 “十里不 同音, 百里不同俗” 的多样文化生态。其中宋朝时随福建移民迁入而带来的汉语方言海南话 (也称 “海南闽语”, 又被更早前入琼的诸语族称为 “客语”), 是在漫长的历史进程中, 不同 程度与当地其他汉族方言及少数民族语言产生相互影响, 从而形成的一种独特的方言, 通用 于广东雷州半岛、新加坡、泰国、马来西亚、菲律宾、印度尼西亚、美国等琼籍汉人聚居地 区, 也是海南岛上使用范围最广、人数最多的语言, 900 万人口中约有 600 万人在使用。海 南话保存了大量古汉语元素, 如 “汝” 指 “你”, “鼎” 指 “锅” 等等, 因此被称为 “古汉语 的活化石”, 具有珍贵的研究和保护价值。而在中国社会科学院民族研究所研究员欧阳觉亚眼 里, 岛上汉语方言中的富马话更是文化的活化石。根据他 1985 年的实地调查, 富马是海南东 方四更镇的一个村, 村里人数最多的文姓人是当年文天祥家乡的部众, 因抗元失败由江西迁 徙到海南, 至调查时止已传了 27 代, 当时全村只有 1 千多人 ${ }^{[4]}$ 。

海南岛同时因为向海而生, 广纳博收, 近代以来又是多元文化汇聚之地, 因此现代海南 话当中也兼收并蓄了许多外来词, 这使得海南的文化更加多样化。可以说, 海南岛拥有文化 的独特性和多样性，是名副其实的方言宝岛、文化宝岛。

\section{3. 语言是重要的旅游资源}

“读万卷书, 行万里路” 的理想古已有之, 求知不仅来自书本, 更在身临其境、亲身体 验。人们走出去, 或访古寻今, 或探奇揽胜, 或愉悦心情, 都是为了满足自己的精神文化需 求, 这正是旅游者外出旅游的 “文化动机”。在这个意义上, 旅游就是去追寻自己文化的根, 也是去体验别人的文化、去体味 “别人的乡愁”; 旅程就是文化与文化、乡愁与乡愁的对话, 人们沉浸其中, 乐而忘返。在这中间, 语言成为文化对话、乡愁对话的特殊要素。特殊历史 地理环境孕育出的语言具有独特的韵味, 能为旅游目的地平添鬼力。

吴必虎认为语言是最有价值的地域人文景观, 他把对语言的感受, 不管是表现于物质载 体上的印刷物、楹联、牌匾, 还是从日常社会交流中听到的口语表述的地方话, 都用一个概 念来概括, 就是语言景观。通过这个概念, 可以系统地表达或阐述一个地区的语言地图、方 言地图、地名景观、文学艺术景观……他认为, 在语言景观的形成与发展过程中, 过去主导 
力量是各种原因产生的人口迁移, 而现代社会更为常见的动力来自规模宏大、速度快捷、频 率高发的跨文化大众旅游 ${ }^{[5]}$ 。蒋述东将旅游地的语言即方言的旅游价值细分为: 体验地域文 化艺术; 体验旅游地的历史; 体验旅游地地理环境; 体验旅游地民俗; 体验旅游地居民性格 特点 ${ }^{[6]}$ 。陈丽君等提出了一个广义的语言资源概念, 主要包含：语言本体，包括方言; 以语言 为载体的文学作品、影视小品、戏剧等; 语言的书写符号一一文字以及文字的艺术表现形式; 以语言为媒介的非物质文化遗产如神话、史诗等 ${ }^{[7]}$, 并指出, 语言资源具有观赏性、趣味性 和稀缺性特征, 是一种可以开放利用的旅游资源。而早在2003年联合国教科文组织大会就在 巴黎通过了《保护非物质文化遗产公约》, 其中第2条规定的 “非物质文化遗产” 的范围列举 项中，第1项即 “口头传统和表现形式，包括作为非物质文化遗产媒介的语言” [8]，指明语言 在非物质文化遗产中的特殊地位。

可见, 语言及其所承载的文化是旅游资源的重要组成部分, 是具有地域属性特征的非物 质文化遗产的重要表现形式。一个地区语言的特殊性和多样性代表着旅游资源的独特性和多 样性, 有助于增加旅游文化内涵。

\section{4. 部分西方国家和国内部分省市语言保护现状}

然而, 很多附着了丰富地域文化信息的语言, 随着现代化步伐的加快已经消亡或正面临 消亡的危险。联合国教科文组织频危语言问题特别专家组的《语言活力与语言濒危》一文指 出, 在全世界 6000 多种语言中, 约 $96 \%$ 的语言的使用者占人类总人口不到 $3 \%$, 意味着每一种 语言的使用者平均只有 3 万人。全世界 6000 多种语言中, 至少有半数语言, 其使用人口正在 减少，到 21 世纪末，在全世界的大部分地区，约 90\%的语言可能被强势语言取代 ${ }^{[1]}$ 。

有研究者作了这样的类比: 一种语言的消失, 无异于生物圈中一个物种的消失。语言资 源的不可再生性, 喻示了其一旦消失即不可逆转, 而语言的消失意味着文化差异性和丰富性 的缩减, 无疑是人类的巨大损失。但语言的发生发展乃至消失固然有其规律性, 人为干预却 能延缓语言衰亡的速度, 甚至使濒危语言重焕生机和活力。多国政府已有这个共识并出台了 立足本国国情的语言保护政策; 学者们也携起手来, 研究采取各种语言保护措施。

美国自殖民时期开始就强化对印第安语言的同化政策, 直至 20 世纪 30 年代, 印第安教 育中开始出现重视土著语言和文化价值的趋势, 之后经过一些反复, 最终在 20 世纪 90 年代 出台了《美国土著语言法案》, 并采用现代技术, 对印第安语言进行了成效显著的保护和复 活, 土著语言研究也逐渐成为一个学术研究的专门领域, 出现了关注和研究印第安语言的专 家和学者, 编撰和出版了方言词典和许多有影响的著作, 有力推动了美国社会对印第安语的 重视。夏威夷的 Maori 语、佛罗里达的 Mikasuki、密西西比的 Choctaw 等等语言的保护和延 续也取得了很好的效果。美国采取的双语教育制度对保护土著的语言文化起到了重要作用, 夏威夷语及其所承载的文化就成为夏威夷独具魅力的旅游资源 ${ }^{[9]}$ 。

在加拿大, 克里人和其他原住民语言一度被同化的现象十分严重。法国和英国的殖民者 进入加拿大后, 先后建立起殖民地, 在原住民中推行法语和英语。基于对民族多样性的认识, 除了推行英法双语政策, 加拿大联邦政府在 1971 年颁布实施了 “多元文化政策” ，以鼓励和 保护所有加拿大的传统语言, 并规定原住民子女可以要求用印第安语进行教育。克里人对自 己的语言和文化高度自信, 和其他原住民一直在不解努力, 积极采取各种措施竭力保护和发 展本民族的语言和文化。加拿大联邦和各级政府、大学和研究机构也在相关政策、法律、法 规支持下, 实施保存、复兴克里语言文化项目。克里人通过克里语方案项目不但保存了自己 的语言, 同时也维护了文化与传统, 特别是增进了学生的学习成就, 带动了整个民族的提升, 进而也强化了民族自信心与认同感 ${ }^{[10]}$ 。

法国1992年《宪法》规定法语为法国唯一官方用语, 但法国政府鼓励保留地区的语言和 文化, 每年的政府预算里有专门经费用于方言保护和推广。学校里开设方言课程; 电视节目 里有方言新闻, 屏幕下方标法文字幕; 居民在家里讲方言。澳大利亚实行的是多元文化主义 
政策，这个理念也指导着政府语言政策的制定和实施，如1987年颁布的《语言问题国家政策》 包括支持土著语言教学，开展双语及双文化教育等 ${ }^{[11]}$ 。

语言资源缩减是世界性问题，我国党和政府高度重视语言资源保护工作。《国家中长期 语言文字事业改革和发展规划纲要（2012-2020年）》将 “科学保护各民族语言文字” 列为主 要任务, 强调重点开展 “语言国情调查” “各民族语言文字科学记录和保存” “少数民族濒 危语言抢救和保护” 等工作 ${ }^{[1]}$ 。2015年5月, 教育部、国家语委印发了《关于启动中国语言资 源保护工程的通知》, 决定在全国范围开展以语言资源调查、保存、展示和开发利用等为核 心的重大语言文化工程, 这标志着我国从国家层面以更大范围、更大力度、更加科学有效的 方式来开展语言资源保护工作 ${ }^{[12]}$ 。山西、浙江、福建、重庆被教育部列为启动该项工程的首 批 4 个省市。

浙江省档案局早在 2011 年 11 月正式发布《关于开展浙江方言语音档案资料建设工作的通 知》, 启动全省范围的浙江方言语音档案数据库建设工作 ${ }^{[13]}$ 。省档案局牵头, 各地档案部门 参与, 以音像和文本两种形式来记录保存浙江各地方言, 工作中强调语料的可靠性和方法的 科学性。其工作经验是：领导重视、有序推进; 立体宣传、合力造势; 公众参与、互动良好。

2016 年初，湖北省宜昌市档案局在全市范围内启动了方言建档工作，用音视频方式记录 全市 13 个县 (市、区) 的主流方言, 建成了以方言理论研究成果、主流方言记录成果、方言文 化转化成果为主要内容的宜昌方言档案综合数据库 ${ }^{[14]}$ 。其工作方法是: 统一思想认识, 争取 各方支持; 严密组织实施, 扎实推动落实; 把握关键要素, 着力打造特色; 系统整合提炼, 形成文化产品。

在中国知网输入关键词 “方言” “保护” 模糊搜索，得到1575条结果; 添加关键词 “行 动” 再模糊搜索, 除了上述浙江、湖北两省, 报道方言保护行动的还有上海和青岛; 其他关 键词和百度搜索又发现, 江西、天津于2016年启动了汉语方言保护项目。但总体来看, 目前 国内方言保护现状是学术研究多、实际行动偏少, 这与我国多民族、多方言, 城镇化与民族 融合加速促使语言同化加快的国情是不相称的。究其原因, 个人认为一是对推广普通话政策 的误解; 二是对语言是文化载体的认识不足; 三是持自然淘汰观点的人群不少, 其中不乏专 家学者; 四是语言自觉自信尚未建立起来。普通民众认为国家推广使用普通话, 就是要实现 语言的大一统, 各种謷牙诘曲的方言确实有碍沟通, 用处也不大, 不如弃之不用; 普通民众 对于语言是文化载体的认识并不清晰, 即使意识到了, 也大多认为文化消失与自己的生活并 无多少关系, 或其消失也不是自己所能左右, 缺乏自觉保护意识; 部分语言研究者认为语言 群落和生物群落一样, 其发展和延续是一个优胜劣汰过程, 弱势语言无法与强势语言抗衡就 任其自然消失; 虽然党和政府号召民众增强文化自信, 但只要不能厘清语言自信、民族自信 与文化自信之间逻辑关系，文化的自觉自信就难以落到实处。

\section{5. 海南方言使用现状及其原因}

虽然据称海南岛上有近 $70 \%$ 的人口使用海南话，但实际情况却并不那么乐观。据宋安琪 2015年对祖父母、外祖父母、父母、本人籍贯都属海南的城乡中小学生语言使用状况的调查, 在海南省会海口地区有超过一半的海南籍学生最先学会的是普通话, 如把同时习得普通话和 海南话的学生也算上, 那么把普通话作为第一语言学习的学生比例达到了 $76.49 \%$, 这个比例 在县级市区则下降到了 $22.03 \%$; 对于 “你会讲海南话吗” 的回答, 省会地区有 $18.89 \%$ 的海南 籍学生表示完全不会讲海南话, $35.02 \%$ 表示只会讲一点海南话, 只有 $46.08 \%$ 的海南籍学生会 讲海南话。调查结果说明城市化越高的地区, 把普通话作为第一语言习得的比例就越高, 在 农村地区则仍有 $85 \%$ 的学生最先学会的是海南话 ${ }^{[15]}$ 。但随着城市化进程加快, 可以预见, 这 一比例将在短期内再度降低。另外, 一个突出的现象是, 在省会城市, 英语习得被前移到了 “起跑线”上, 学生对英语的掌握程度比海南话高出许多, 这与家长和学校对外语教育的重 视有关, 从根本上看也是迫于我国考试制度的压力。 
海南话由盛转衰是有迹可循的。清末海南人张岳崧主持编纂的道光《琼州府志》记载: “州城惟正语, 村落语有数种。一曰东语, 又名客语, 似闽音; 一曰西江黎语, 即广西梧、 浔等处音; 一曰土军语; 一曰地黎语, 乃本土音也。大率音语以琼山郡城为正, 使乡落一切 渐相染习，皆四通八达之正韵也 ${ }^{[16]}$ 。” 可见清末年间主要以 “似闽音” 的 “客语” 海南话为流 通语言, 其中以州府所在地的琼山口音为正统音, 州府经济的发达带来其语言的强势。建国 后 “无文昌不机关”, 海南话中的文昌音又曾经作为海南话的 “标准音”, 在广播电台播出海 南话节目。但从 20 世纪50 年代百万农垦大军南下拓荒, 到60、70 年代知识青年上山下乡, 以及 80 年代末改革开放 10 万人才下海南, 解放后历次大规模的政策性人口迁徙都在大手笔改 写海南的语言格局, 此消彼长, 普通话迅速占领了语言制高点, 相应地, 海南话的颓势越来 越凸显。“海南人不会讲海南话” 成了一个网上热议的怪现象, 而这个变化过程只用了短短数 十年时间，正如英国伦敦大学玛丽皇后学院教授大卫・阿德格尔(David Adger)所说: “语言是 一种非常脆弱的东西, 仅仅一代人的时间, 就会大量遗失。”

普通话后来居上占据了绝对优势, 本地方言逐渐成为稀缺资源, 首先, 这种现象符合语 言发展的一般规律。“人类语言庞杂多样不能互通所产生的 “语言障碍” 制约了人类的交往, 人类要扩展自己的交际范围和交际能力, 就必须要实现 “语言归一” ” ${ }^{[17]}$ 。海南境内多种语 言、方言并存, 居民间相互难以沟通现象确曾存在, 我国推广使用普通话正契合了这种 “归 一” 要求, 因此普通话在海南迅速推广应用开来, 效果显著。其次, 本地语言族群对所持方 言缺少了解以致缺乏自信, 即使是比岛上其他语言显得强势的海南话也底气不足, 按海南本 土作家崽崽的说法: “海南岛孤悬海外, 经济和文化都有点势单力薄。海南人都不愿意说海 南话, 说明海南话的羞涩。” 对自己的方言感到羞于启齿, 感觉其落后、粗野、不上台面, 这是居民 “集体无意识” 主动放弃本地方言的内因。最后, 当前我国语言保护意识不强, 政 府介入不主动，语言政策制定和推动不力，资金投入缺乏。

\section{6. 国内外语言保护经验对海南的启示}

为扭转海南方言逐渐衰微的颓势, 有识之士一直在努力促成保护方案的出台, 海南省政 府已收到陈祎平等政协委员 “关于进一步保护与传承海南方言的建议” 的提案, 其中提到: “对 于海南方言, 不仅有保护、防止流失的问题, 还有一个利用和开发的问题。新加坡作为移民 国家，确立了科学的语言规划观，尤其在 “利用语言资源” 方面成效显著。特色即是资源, 是不可替代的旅游资源, 加大重视和挖掘海南方言文化的力度, 不仅是一种社会责任, 也是 特色文化建设的需要。” “海南岛作为公认的 “方言宝库” , 更要加大海南方言的保护和传 承力度, 为国际旅游岛的建设提供文化支撑 ${ }^{[18]}$ 。” 在博鳌亚洲论坛 2016 年年会上, 知名主持 人汪涵接受海南特区报记者独家专访时表示, “海南话” 以及黎族、苗族等少数民族的方言, 与全国其他地方的方言一样, 都处于一种亟待进行 “抢救性” 保护的状态, “海南的方言特 别宝贵, 按照计划, 在做完湖南的方言调查项目后, 我就会着手对全国的方言进行调查、整 理和保护, 海南方言的保护我是一定会做的 ${ }^{[19]}$ 。”

\section{1 国家政策支持, 政府部门作为}

纵观国内外语言保护行动, 要想取得实效, 政府的语言规划、语言政策制定以及经费支 持是最可靠的保障之一。继《国务院关于推进海南国际旅游岛建设发展若干意见（国发 [2009]44 号) 》 (下称《意见》) 印发后, 海南省委省政府作出贯彻实施该《意见》的决定, 其中提到了 “加强对文物及非物质文化遗产的保护” ; 已于 2010 年通过的《海南省实施〈中 华人民共和国国家通用语言文字法>办法》中也有关于 “各民族有使用和发展本民族语言文字 的自由” 的规定; 海南省教育厅在给陈祎平等委员 “关于进一步保护与传承海南方言的建议” 的政协提案的答复中指出： “海南方言是我国地方文化的组成部分, 是海南人的一张名片, 保护和继承海南方言有利于海南文化和社会的发展, 有利于推动海南国际旅游岛的建设, 有 
利于吸引外地海南人及其后代的乡情回归, 增强国内外海南人的凝聚力”, 并表示 “我省 2016 年启动了中国语言资源保护工程海南项目, 将这项工作列入教育工作规划, 开展以海南方言 调查、保存、展示和开发利用等为核心的各项工作。” 具体措施是加大研究和挖掘力度, 鼓 励有条件的大学设立海南方言研究机构, 给予相应政策、资金支持, 鼓励出版发行相关研究 成果; 搜集、整理海南方言民谣、民间故事、地方戏曲; 鼓励、挖掘海南方言文艺创作 ${ }^{[18]}$ 。

由此看来，政府从政策层面上对方言研究和保护工作进行了肯定和承诺，但政策宣传力 度不够, 公众知晓度不高; 参与人群局限性大, 未广泛深入发动全社会参与; 政策存在一定 盲区, 如重语料保存而轻传承与再生、对人才培养重视不够、语言资源产业化开发意识不足 等。

海南作为国际旅游目的地, 其引以为傲的热带沙滩、原始森林并非独有, 在世界其他地 方也能找到, 甚至海南也未必比别人有优势。美国的夏威夷群岛, 纬度与海南接近, 自然资 源相似, 但夏威夷的境外游客数量是海南的 3 倍以上, 入境旅游者占游客总数比重是海南的近 18倍, 是名副其实的国际旅游目的地。相比之下, 海南还有很大差距。夏威夷是以其独特的 文化吸引旅游者的, 著名的 “阿罗哈” 文化、草裙舞等成了夏威夷文化的象征 ${ }^{[20]}$; 而海南除 了热带自然风光, 其他与中国内地无异, 并未给旅游者留下深刻的文化印象。夏威夷的官方 语言是夏威夷语和英语。在夏威夷, 小学生们的文化背景差异巨大, 他们可能来自日本、中 国、韩国、印度、越南、泰国, 甚至遥远的非洲, 但所有的孩子都会学习一种语言一一夏威 夷语, 学习弹奏一种乐器——夏威夷四弦琴 ( Ukulele)。每个学校都会有夏威夷的老祖母带 领孩子们唱夏威夷歌谣, 将点点滴滴的夏威夷文化传播给他们。李燕琴等指出: “文化是一 个旅游目的地的灵魂。各具特色的文化为自然注入了更加丰富的内涵。夏威夷在旅游开发中 最成功的经验之一就是对本土文化的保留与保护, 这是吸引旅游者非常重要的因素。”同时 强调, 夏威夷旅游发展的主体是 “保护本土文化” 和 “让当地人受益”，“它们是旅游发展 不可动摇的基础和根本”, “很多学者、旅游业界人士以及政府官员都开始注意到政府的重 要作用” ${ }^{[21]}$ 。政府作用的表现之一在于实施双语教育。双语教育不仅有利于保护夏威夷本土 文化，本土文化所带来的旅游收益也造福了当地人民。

海南建设国际旅游目的地，同样应该在政府主导下打好文化这张牌。本土文化的多样性 才是海南最好的旅游资源, 而本土文化就蕴藏在这 “鸟语”一般的本地方言中。以海南话为 例, 它是闽南语的一支, 但与闽南语其他支脉已无法交流, 它发展变迁的历史包含了丰富的 地理、人文因素, 这是十分值得关注和研究的领域; 海南话中保存了许多古音古韵, 这也是 考古、文博领域有待进一步发掘的新课题。2017年, 同为闽南文化源流的厦门鼓浪屿申请世 界文化遗产项目获得成功。在世遗大会审议的文件显示： “鼓浪屿见证了清王朝晚期的中国 在全球化早期浪潮冲击下步入近代化的曲折历程, 是全球化早期阶段多元文化交流、碰撞与 互鉴的典范, 是闽南本土居民、外来多国侨民和华侨群体共同营建, 具有突出文化多样性和 近代生活品质的国际社区 ${ }^{[22]}$ 。”厦门市委、市政府用时9年, 举全市之力推进鼓浪屿申遗工作。 这对海南是又一个有价值的启示。

因此, 海南省政府应当高瞻远瞩, 作为主导力量, 有关部门主动作为, 扎实推进语言保 护工作的落实。在海南, 建议按普通话一一方言一一外语的权重顺序做好机关、学校、企事 业单位、服务行业的语言使用工作, 非官方环境、工作场合应大力提倡使用方言。普通话的 老大地位不容动摇, 语言归一有利于民族团结、社会和谐和国家统一。但在旅游目的地, 外 语是否比方言更重要值得商榷。除涉外机构、接待外宾场合确需使用外语满足商务功能外, 其他区域和场所并非一定要使用外语。首先, 排除商务活动外宾, 境外游客来海南首先是向 往这里特殊的文化氛围, 他们对语言不通的困难会有一定心理准备, 不会期望如同在本国语 环境下一样交流顺畅, 有些人还会准备一些中文常用词句以敷不时之需; 其次, 人们可以借 助肢体语言、国际通行网络语言或纸笔交流, 以解语音交流障碍; 再次, 说得严重一点, 我 们除了有低估境外游客交流能力的可能外, 还在一定程度上有 “示弱” 倾向一一对本民族、 
本地区语言文化不自信, 正如海南本土作家崽崽所说的海南方言在普通话面前 “差涩” , 倘 若普通话在外语面前也差涩, 我们的民族自信如何自处? 最后, 近些年来, 汉学热在世界各 地兴起, 古老灿烂、博大精深的中华文化正被越来越多的国家人民接受和喜爱, 我们更没有 理由不为自己的语言感到自信和自豪。

\section{2 将海南方言及其文化融入学校教育教学}

学校是语言文化传播和教育的主阵地, 同时应该成为方言及其文化教育渗透的重要领域。 有研究者提出, 我国应借鉴国外经验, 实施双语教育, 以利于民族语言和方言的传承和发展。 根据海南地域小而且并存多民族、多方言的实际, 双语教育在短期内实施起来恐怕有一定难 度, 但可以在日常教育教学中融入本地方言, 加入文化背景阐释, 从小培养学生对方言学习 和研究的兴趣。例如普通话的 “开水”, 用海南话讲即 “沸水”; 普通话的 “干饭”, 海南话对 应为 “粠”。一个 “沸” 字栩栩如生, 一个 “粠” 字古色古香, 古韵悠扬的海南话具有无穷的 文化鬼力。方言知识融入到学校日常教学不但无损普通话, 还能和普通话形成比较, 增加语 言学习乐趣。普通话和方言并行不悖也有利于孩子们从小习惯多元文化的比较和融合, 实际 上也是跨文化思维的启蒙。

\section{3 激发民众对本地方言高度的自觉自信}

通过多种形式的宣传教育, 唤醒民众传承和保护方言意识, 激发其对本族群、本地区方 言高度的自觉自信。家庭是方言传承的第一环境, 也是重要堡垒; 使用方言还能融洽亲情, 营造和谐的家庭氛围。如果家庭内方言的代际传播断裂, 对方言的传承将带来难以逆转的破 坏, 因此应大力提倡在家庭内使用方言。社区也是营造方言使用氛围的主阵地。社区教育要 充分重视方言的传承和保护, 开设的课程应包含方言和本土文化课, 应以方言作为主要教学 语言; 社区干部要以身作则, 发挥引领作用, 倡导社区工作和人际交流使用方言作为主要媒 介, 相应地, 普通话可以退居其次。

\section{4 鼓励方言领域的学术研究和人才培养}

在海南, 除了 “海南人不讲海南话” 之外, 还有一个令人遗憾的现象是鲜少有海南人研 究海南自己的方言和文化, 反而是岛外甚至国外人士对这里的人文研究起步更早、成就更大。 政协专门委员会 “关于设立海南省黎学研究所的建议” 提案中提及, 黎学研究从 20 世纪初开 始逐渐兴起, 到 40 年代即出现数百种关于海南岛黎族的专著、文章和研究报告, 仅日文研究 资料就有上百种。其中德国人类学家史图博被尊为黎学研究的奠基人, 他的《海南岛民族志》 是第一本用民族学理论和方法系统研究黎族的经典著作。该提案也指出当前黎学研究存在的 问题: 一是研究人才缺乏; 二是被国内外学术界公认有分量的研究成果不多; 三是没有形成 指导全省黎学研究的中心和基地 ${ }^{[23]}$ 。

在中国知网上查询到的海南黎学研究文献作者, 绝大多数不是海南人, 更不是黎族人; 对海南话变迁史及其与福建闽南语的比较研究也凤毛麟角, 以关键词 “海南话” “变迁” 模糊 搜素, 只得到一条结果。说明海南语言和文化研究从本地研究者到研究成果都十分贵乏, 人 才危机显现。因此, 设立专业研究中心和专项基金项目, 鼓励和支持海南方言领域的学术研 究和人才培养迫在眉睫, 尤其应大力支持本地籍人才培养。不言而喻, 本地人研究本地方言 和文化具有得天独厚的优势, 因为从小浸润其中, 方言里的非正式语、浐语、俚语、俗语、 尾音甚至腔调所蕴含的文化味道都已经深入骨髓。

人才的培养极端重要, 除了研究型人才培养, 还应提高社区干部方言水平, 加大方言教 学、播音、主持、解说、导游等人才培养力度, 对以方言为媒介的各种民俗民间文化艺术人 才培养提供财力支持, 使海南方言在更多维度上得到继承和传播。至于人才培养的途径, 除 了口传心授, 在可能情况下应设立相关机构, 编写简明实用、图文结合的文字教材, 制作便 于学习模仿和易于传播的音视频资源。 


\section{5 采取及时科学的、现代化的方言保护措施}

美国在 20 世纪 90 年代即采用技术手段保护和复活印第安语言; 荷兰莱顿大学南亚与中 亚研究中心教授范 - 丹姆 (Van Driem) 和他的团队从 20 世纪 90 年代起在 20 年时间里整理了 一百多项喜马拉雅地区语言的详细记录, 不仅包括单词列表、范式和短语, 还有神话传说、 个人叙述与对话文本等资料, 为研究喜马拉雅地区濒危语言提供了完整可靠的记录 ${ }^{[24]}$ 。我国 的浙江、湖北宜昌等省市均采用文本和音视频记录和保存方言资料和调查研究成果。浙江省 强调语料的可靠性和方法的科学性。随着老一代方言使用者的逐渐减少, 保证语料可靠性的 任务变得越来越紧迫。在科学技术发展为方言保护提供了先进技术手段、为建立可靠语料库 提供最大可能的条件下, 海南同样需要尽快做好行动规划, 组织可靠的语料, 让那些行将消 失或已消失的语料重现生机。福建博物院梁长福指出: 地方博物馆根据自身公益性质, 有为 这项工作的开展实施帮扶的责任与义务; 地方博物馆的软硬件资源可以为这项工作的深入提 供有力的技术支持, 并能进行有效的成果展示和良好的保存维护。博物馆也是游客集中之地, 是展示本地文化精髓的重要场所。

\section{6 方言作为第二语言应用于公共场所}

公共场所应将方言作为第二语言来使用。主要城市公交车、车站码头、机场等客流量大 的场所可采用普通话、方言、英语三语制。香港机场和香港航空这方面的经验值得借鉴。香 港机场候机楼采用的是粤语、普通话、英语三语制; 香港航空机舱广播也采用三语制, 分别 是粤语、普通话、目的国语言 (如飞往日本的航班使用日语)。香港在公共场所使用粤语方言 体现了本族语的主体地位, 这是值得尊重的做法。目前国内机场和国内线路航班基本上全部 采用普通话、英语双语播音; 城市公交车报站也基本采用普通话或普通话、英语双语制。在 海南的海口、三亚、儋州三个主要城市随机搭乘市内公交车发现: 海口市内公交车报站采用 双语 (普通话、英语); 三亚市采用普通话; 儋州市采用双语 (普通话、儋州话)。除公共交 通外, 海口其他公共场所也均未发现有使用方言情况。建议海口、三亚改用普通话、方言、 英语三语制, 既体现两地所属方言区的主体地位, 展现方言的独特鬼力, 又满足海南作为国 际旅游目的地对语言实用功能的要求; 其他市县公共场所使用普通话和方言即可。

\section{7 利用各种媒体多方位宣传助推}

各类媒体受众巨大, 尤其正值媒体融合成为主流趋势, 用户参与和互动维度提升加速的 当下, 方言传承可以借助媒体力量进行推广。海南应广泛借鉴国内外经验, 在广播电视等传 统媒体增设方言栏目, 对已停播或时段不佳的方言栏目进行恢复和调整; 在电脑、手机、数 字电视等新媒体终端传播方言类节目; 鼓励传统纸媒刊载方言类文学艺术作品; 大力扶持和 培养本地方言作家、歌手、演员创作演出本地方言文艺作品, 为本地群众和外地游客提供丰 富的文化大餐，同时通过多种媒体把海南方言和文化传播到更广的空间。

\section{8 通过开发利用方言资源为弱势语言注入活力}

国家教育部、国家语委2015年印发的《关于启动中国语言资源保护工程的通知》指出了 要 “开发利用” 各地语言资源, 表明语言资源可以进行产业化开发。“对于语言资源来说, 合 理的开发利用就是一种保护, 因为它和其他资源不同, 是用进废退, 越使用和开发, 其增量 就越大，持续再生力就越强” [25]。语言资源产品大体上分为视觉产品如楹联、手工艺品; 听 觉产品如歌曲, 视觉+听觉产品如戏曲表演等三类。例如海南有一种用草编制的类长方形可背 亦可提的大肚置物袋，什么东西都可以往里装，是名副其实的 “杂物袋”, 海南话音 “gādú”。 人们取笑姑娘挑来挑去最后挑到的并非如意郎君时会讲 “择来择去择入 “gādú”。“gādú” 作 为一种本地特色生活用品现已基本消失不见, 人们开发旅游纪念品时却可以让其重见天日, 方言读音 “gādú” 可以印于其上, 加上导游、导购的解说, 即成为 “视觉+听觉” 旅游产品, gādú文化也将重拾生命力。 


\section{7. 结束语}

语言作为一种重要的文化资源, 同时也是非物质文化资源的重要组成部分，对于传承文 明和保持文化多样性具有重要作用。面对当前语言多样性遭受破坏导致文化多样性缩减趋势, 政府、有关部门和社会各阶层应以时不我待的危机意识行动起来, 采取有效措施保护弱势语 言和濒危语言。海南作为国际旅游目的地和中华文化活化石宝库, 更要保持区域语言生态的 特殊性和多样性，向世界展示海南多元文化的独特鬼米力。

\section{致谢}

本文为海南省哲学与社会科学规划项目《文化引领在国际旅游岛建设中作用及机制研究》 （HNSK（YB）16-89）的阶段性成果之一。

\section{References}

[1] Tian Lixin, On the Origins and Significances of the Project for Protecting Language Resources of China, Applied Linguistics, vol.4, pp. 2-9, 2015.

[2] Deng Yanchang, Liu Runqing, Language and Culture: Comparison of English and Chinese Culture, Foreign Languages Teaching and Research Press, 1989.

[3] China's National People's Congress Network, The Convention on the Protection and Promotion of the Diversity of Cultural Expressions, CCD, 2017-12-11, Haikou, available at http://www.npc.gov.cn/wxzl/gongbao/2007-02/01/content_5357668.htm.

[4] Ouyang Jueya, Hainan dialect islands: a treasure house of the living fossils of immigrant culture, Hainan Daily, pp.03, Aug. 23, 2010.

[5] Lian Yihui, Multi Views on "Language Protection", Chinese Journal of Language Policy and Planning, vol.8, pp.5-6, 2017.

[6] Jiang Shudong, On the Tourism Value and Experience Approach of Dialects, Journal of Chongqing University of Education, vol.28, pp.29-32, 2015.

[7] Chen Lijun, Hu Fanzhu, Language Resource: A Tourism Resource Urging Development, Tourism Science, vol.24, pp.22-27, 2010.

[8] Tian Youlan. On the Significance of Protecting Language Diversity, Thinking, vol.38, pp. 147-148, 2012.

[9] Li Yingzi, Research on Language Policy in USA, Tianjin: Nankai University, 2009.

[10] Gao Xia, Evolution of Cree Language Policy in Canada and Language Protection, Research on Higher Education of Nationalities, vol.4, pp.21-25, 2016.

[11] Wang Jian, Enlightenment from the Protection of Dialects in Western Countries, Journal of Zhengzhou Institute of Aeronautical Industry Management( Social Science Edition), vol.30, pp.114-115, 2011.

[12] Li Li, A Preliminary Discussion on the Protection and Construction of Local Language Resources in Jinhua - Taking the Protection of Yiwu Dialect as an example, Examination Weekly, vol.86, pp.17-18, 2016.

[13] Feng Lin, Ding Tianxing, Recording the Vanishing Dialect, Zhejiang in Action, Zhejiang Archives, vol.2, pp. 5-10, 2012.

[14] Gong Yaqin, Li Li, Speak the Dialect, Cherish the Nostalgia - Dialect Filing Project Documentary in Yichang, Hubei Province, China Archives, pp.003, Apr. 10, 2017. 
[15] Song Anqi, A Comparative Study on the Language Status of Urban and Rural adolescents in the Process of Urbanization - Taking Primary and Middle School Students in Hainan as an Example, Language Planning, vol.12, pp.31-32, 2015.

[16] Sun Hui, Huang Qingwen, The Change of Hainan Island's General Language - from "Qiongshan tone" to "Putonghua", Hainan Daily, pp.B03, Sep. 16, 2013.

[17] Zhang Wanxin, etc, Exploratory Dialogue on the Unity of Human Language, Invention \& Innovation, vol.4, pp.20-21, 2004.

[18] Chen Yiping, Li Renjun, Su Ping, Du Liyin, Suggestions on Further Protection and Inheritance of Hainan Dialect, 2018-01-11, Haikou, available at http://www.hainan.gov.cn/zxtadata-7112.html.

[19] People's Daily Online, Who has "stolen" the Dialects in Hainan? 2017-04-06, Haikou, available at $\mathrm{http}: / /$ hi.people.com.cn/GB/374508/375779/376068/index.html.

[20] Suiyi 800, The Gap between Hainan Island and the International Tourism Island by Comparing with Hawaii, 2017-12-30, Haikou, available at http://bbs.tianya.cn/picall-hn-104825.shtml\#p=269148312, 2017-02-14.

[21] Li Yanqin, Liu Liping, Applying Hawaii's Tourism Industry Sustainability Principles to Hainan, Tourism Tribune, vol. 26, pp.16-24, 2011.

[22] Hong Buren, Memory of Gulangyu, Journal of the Chinese People's Political Consultative Conference, pp. 011, July 17, 2017.

[23] People's Daily Online, Gulangyu Islet's Success in Preserving Its Heritage: Preserving Its Unique Cultural Heritage, 2018-02-16, Haikou, available at http://news.k618.cn/roll/201709/t20170917_13132749_1.html, 2017-09-17.

[24] Compiled by Ma Wenyan, Ba Zhanlong: Multinational Scholars Hand in Hand to Protect Endangered Languages, Chinese Social Sciences Newspaper, pp.A03, June 11, 2012. [EB/OL]http://blog.sina.com.cn/s/blog_3ca1700e01013tjt.html, 2012-06-12。

[25] Fan Junjun, Xiao Zihui, The Outline of Language Resources, Social Sciences in Nanjing, vol. 4, pp.128-132, 2008. 